\title{
Short Stature due to SHOX Deficiency: Genotype, Phenotype, and Therapy
}

\author{
Gerhard Binder \\ University Children's Hospital, Pediatric Endocrinology and Diabetology, Tübingen, Germany
}

\section{Key Words}

Leri-Weill syndrome $\cdot$ Dyschondrosteosis •

Haploinsufficiency $\cdot$ Madelung deformity $\cdot$ Idiopathic short stature

\begin{abstract}
SHOX deficiency is a frequent cause of short stature. The short stature homeobox-containing gene resides in the telomeric PAR1 region on the short arm of both sex chromosomes and escapes $\mathrm{X}$ inactivation. For this review, abstracts of 207 publications presented by PubMed for the search term 'SHOX' were screened. Heterozygote SHOX mutations ( $80 \%$ deletions) were detected in $2-15 \%$ of individuals with formerly idiopathic short stature, in $50-90 \%$ of individuals with Leri-Weill dyschondrosteosis, and in almost $100 \%$ of girls with Turner syndrome. Mutational analysis is primarily performed by MLPA analysis followed by gene sequencing if necessary. SHOX is a nuclear protein that binds to DNA and acts as a transcriptional activator. Orthologs are present in many vertebrates but not in rodents. Gene expression starting as early as 33 days postconception in humans is predominant in the mid portion of the buds and in the first and second pharyngeal arches. In the growth plate, hypertrophic chondrocytes express SHOX where it seems to have antiproliferative potency. The penetrance of SHOX deficiency is high, but its clinical expression is very variable becoming more pronounced with age and being more severe in fe-
\end{abstract}

males. Growth failure starts early during the first years of life and the height deficit present at preschool age seems not to deteriorate further. The mean adult height is -2.2 SDS. Auxological analysis of the body proportions (mesomelia), the presence of minor abnormalities, and the search for subtle radiographic signs are important keys to the diagnosis which has to be confirmed by genetic analysis. The growth-promoting effect of GH therapy approved for individuals with SHOX mutations seems to be equal to the effect seen in Turner syndrome.

Copyright $\odot 2011$ S. Karger AG, Basel

\section{Introduction}

Statural growth and adult height are regulated by a complex system of endocrine factors including the GHIGF-I axis as the most prominent system but also by intrinsic nonendocrine systems of the skeletal bones which guarantee the correct balance of proliferation and differentiation of chondrocytes for physiological extension in length and width. The physiology and the disorders of this bone-intrinsic regulation are less well understood than the endocrine system. Although more than 300 different monogenic disorders of the bone which are frequently associated with short stature and bone dysmorphology have been described, only a handful of disorders are so frequent that the clinician and the radiologist are

\section{KARGER \\ Fax +4161306 1234 \\ E-Mail karger@karger.ch}

www.karger.com

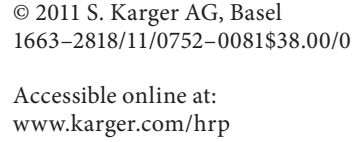

Prof. Dr. Gerhard Binder

Pediatric Endocrinology, University Children's Hospital

Hoppe-Seyler-Strasse 1

DE-72076 Tübingen (Germany)

Tel. +49 7071298 3781, E-Mail gerhard.binder@med.uni-tuebingen.de 
able to recognize the phenotype and make the correct diagnosis. SHOX deficiency is just one monogenic disorder of the bone, but collected evidence supports the notion that this highly variable osteodysplasia is likely the most frequent one.

\section{SHOX Gene}

SHOX - the short stature homeobox-containing gene - was discovered by deletion mapping of the short arm of chromosome X by Rao et al. [1] and independently by Ellison et al. [2] who named the gene PHOG but published later. The gene is located on the very tip of the short arms of both sex chromosomes $\mathrm{X}$ and $\mathrm{Y}$ inside the telomeric part of pseudoautosomal region 1 (PAR1) which comprises around $2.6 \mathrm{Mb}$ (fig. 1). This region contains genes which escape $\mathrm{X}$ inactivation. Because of this circumstance, SHOX is expressed on both sex chromosomes and as far as we know there is no difference between SHOX $(X)$ and SHOX $(Y)$. During the meiosis pairing of spermatogenesis, the $S H O X$ region of PAR1 is a hotspot for very frequent recombination events between the $\mathrm{X}$ and $\mathrm{Y}$ chromosomes [3]. The initial discovery of the gene SHOX was promoted by the known association of short stature with deletions of the short arm of the $\mathrm{X}$ chromosome or small terminal deletions of the short arm of the Y chromosome. Independent from this research, there was a search for the disease gene involved in the dominantly inherited Leri-Weill syndrome or Leri-Weill dyschondrosteosis (OMIM 127300) which revealed linkage to microsatellite DNA markers located in PAR1 next to the discovered SHOX gene: SHOX deletions were found to be causative in Leri-Weill syndrome as well $[4,5]$.

The SHOX gene contains 2 recognized motifs: the homeobox encodes a homeodomain which enables specific DNA binding and gene transactivation of the protein $[1,2]$. In addition, this protein domain is relevant for nuclear translocation [6] and for dimerization of SHOX [7]. The second motif encodes for the C-terminal-located OAR domain which is also relevant for the transactivational activity of SHOX [8]. The SHOX mRNA is encoded by 7 exons $(1-5,6 \mathrm{a}$, and $6 \mathrm{~b})$ encompassing about $40 \mathrm{~kb}$ of genomic DNA (fig. 1). Alternative splicing results in 2 products: SHOXa and its shortened version $\mathrm{SHOXb}$ which lacks the information for the OAR domain and is therefore not active as a transcriptional activator. SHOX is a member of the paired-like type of homeobox-containing genes $[1,2]$. Homeobox-containing genes play im- portant roles during embryogenesis and development by regulating pattern formation in time and space.

SHOX gene function is dosage dependent: the loss-offunction mutation of one SHOX allele (haploinsufficiency) results in the disorder of SHOX deficiency which causes growth failure. The most frequent SHOX mutations found are gene deletions of different size which encompass the SHOX gene itself [9] or a regulatory enhancer region which is located $50-250 \mathrm{~kb}$ downstream of the coding region [10]. These deletions account for around $80 \%$ of all mutations. The other gene defects found are missense and nonsense mutations which are spread all over the gene, but most of them are located within exons 3 and 4 which encode the functional important homeodomain (fig. 1). These mutations are predicted to cause inactivation of the protein or to block nuclear translocation or dimerization of SHOX [7]. Very recently, partial and complete $S H O X$ duplications with a size range from 13 to $346 \mathrm{~kb}$ were reported in patients with short stature and the SHOX deficiency phenotype [11, 12]. Such chromosome rearrangements are thought to cause a disruption of the interaction between the enhancer regions and the promoter of SHOX resulting in a decreased transactivation of gene expression $[11,12]$.

The prevalence of SHOX mutations in children with so-far-unexplained short stature (idiopathic short stature) has been estimated according to SHOX mutation screening studies. Estimates differed from cohort to cohort and increased with the surge of more sensitive genetic methods for the detection of small deletions and with the knowledge of the functional importance of the enhancer region downstream of the SHOX gene. Estimates for prevalence in short children ranked from 2 to $15 \%$ [13-15]. The prevalence of SHOX mutations in individuals with Leri-Weill syndrome (see below) is around $50-90 \%[16,17]$. Turner syndrome is almost always associated with the loss of one SHOX gene because of the numerical or structural aberration of the $\mathrm{X}$ chromosome associated with this syndrome.

The loss of both SHOX alleles causes the complete lack of SHOX and an extreme phenotype of osteodysplasia called Langer syndrome [18]. This syndrome (MIM 249700 ) is relatively rare in comparison to what could be expected from the estimated prevalence of SHOX haploinsufficiency in short children. The gain of 1 or 2 additional copies of SHOX due to structural aberrations of the $\mathrm{X}$ chromosome can be associated with tall stature $[19,20]$.

The rational genetic approach for detecting SHOX mutations starts with the search for deletions because these 
Fig. 1. The schematic overview shows the chromosomal location of PAR1, the gene content of PAR1 including SHOX, and the 2 different SHOX mRNAs produced by alternative splicing, which contain exons I to $\mathrm{VIa}$ and I to $\mathrm{VIb}$, respectively (intron lengths are not scaled). Homeobox is indicated in turquoise (white in the print version) and the OAR, which is only present in SHOXa, is indicated by the arrow. The frequency and location of point mutations and small deletions/insertions of SHOX are shown at the bottom. The graphic is a compilation of resources taken from publications by Mangs et al. [43] and Blaschke et al. [44].

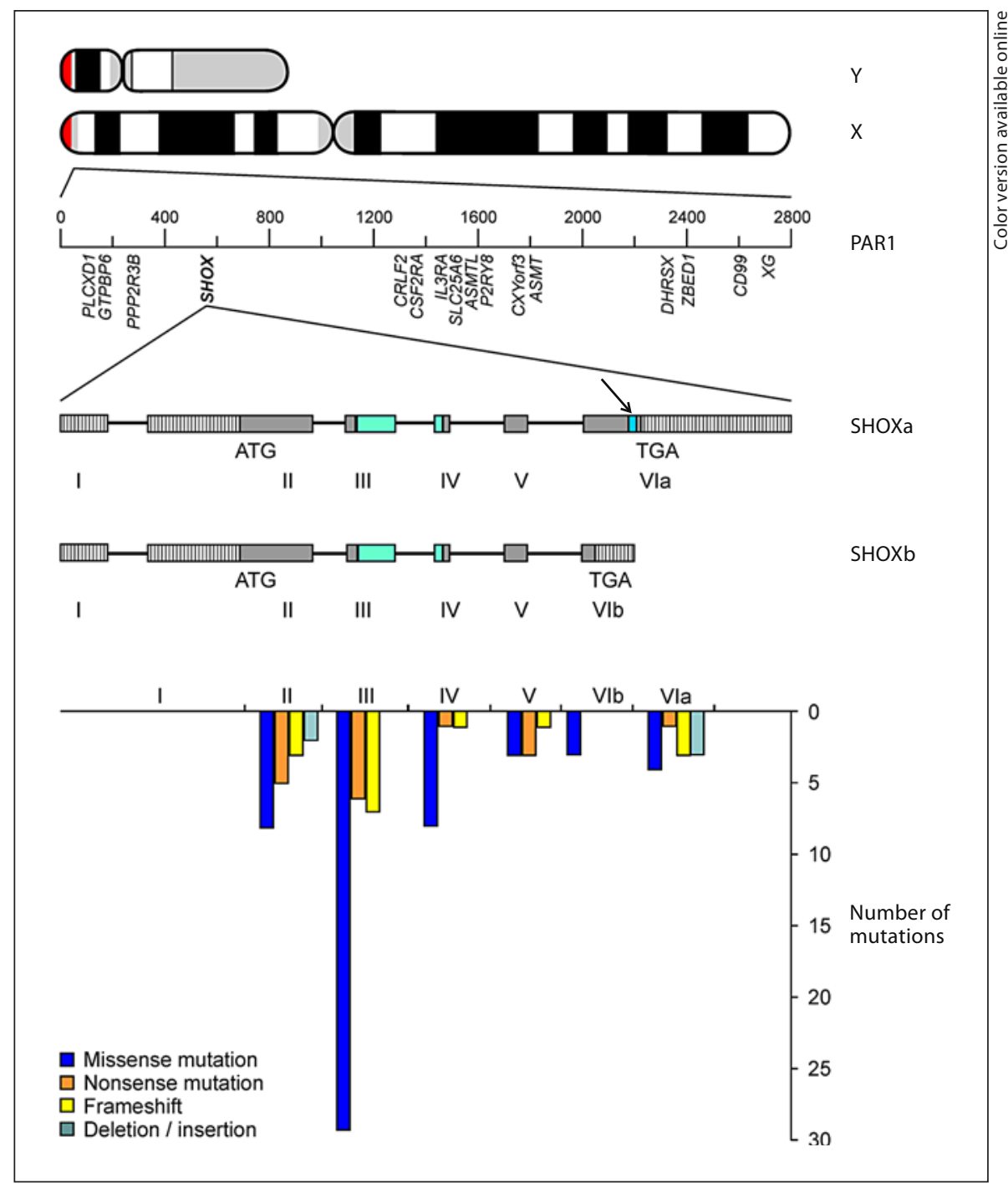

are the most frequent SHOX gene mutations found. For this purpose, the commercially available multiplex ligation probe-dependent amplification (MLPA) analysis has the highest available sensitivity [21]. This method enables the detection and quantification of small deletions in many screening samples relatively fast and is superior to formerly used methods like fluorescence in situ hybridization (FISH) or microsatellite analysis. In the absence of a deletion, direct sequencing of exons and flanking regions is necessary to detect the less frequent missense or nonsense mutations. Until now, 224 unique allelic variants have been reported to the SHOX database (http:// www.hd-lovd.uni-hd.de). The mutational analysis is covered by a patent which is currently held by Bioscientia in Europe and by Esoterix in the USA.

\section{SHOX Protein}

In the case of SHOX, the gene and the protein have the same name. Studies on the biological meaning of the SHOX protein are still scarce and focus on SHOXa which contains 292 amino acids. The main problem is the lack of a rodent ortholog. Therefore, a knockout mouse or rat model could not be established. So far, functional analyses have been performed in chick embryos where an ortholog of SHOX exists [10,22]. Like other homeodomaincontaining proteins, SHOX is a nuclear protein and acts as a transcriptional activator [8]. SHOX specifically binds to the palindromic DNA sequences 5'-TAAT(N)ATTA-3' [8]. SHOX is phosphorylated, with serine 106 being the major SHOX phosphorylation site [23]. 
Analysis using zoo blots revealed that SHOX is present in vertebrates including fish, but it is absent in nonvertebrates [24]. In situ hybridizations in human embryos revealed a very early start of SHOX expression in the developing limb bud at Carnegie stage 14 which is 33 days postconception [24]. The predominant location found was in the mid portion of the developing limb buds and, in addition, in the first and second pharyngeal arches [24]. This expression pattern resembles the locations of the anatomic structures which are affected when SHOX is deficient: the forearm and lower legs as well as maxilla, mandible, and the external ear tract.

Analysis of human growth plates revealed hypertrophic chondrocytes as the main producer of SHOX [25, 26]. In osteogenic cell line U2OS as well as in primary oral fibroblasts and primary chondrocytes, SHOX overexpression causes blockage of the cell cycle with proliferation arrest and apoptosis which may indicate that the main effect of SHOX is to promote differentiation and to stop proliferation of the hypertrophic chondrocytes in the epiphyseal growth plate [25]. A search for downstream targets has so far detected brain natriuretic peptide (BNP) as a gene whose expression is stimulated by SHOX [27]. So far, the biological meaning of this finding is unclear.

Histological examination of the epiphyseal plate of the distal radius in patients with Leri-Weill syndrome and SHOX haploinsufficiency revealed a disorganization of the hypertrophic chondrocytes which built cell nests instead of columns, given a plausible explanation for insufficient growth in length and bowing of the radius in SHOX deficiency [28].

\section{SHOX Deficiency Phenotype}

SHOX deficiency causes short stature with a highly variable phenotype which is frequently nonspecific in preschool children because the main characteristics of mesomelic disproportion of the limbs and Madelung deformity of the forearm develop over time and appear during the second decade of life or never [29-31]. Therefore, the clinical spectrum observed resembles different phenotypes: short stature with no specific findings other than short stature (so-called idiopathic short stature), short stature with subtle auxological and radiological findings, and the full picture of Leri-Weill syndrome (osteochondrosteosis). Characteristic signs are more frequent and more severe in girls, a finding which may be explained by the presence of higher estrogen levels in females [32].
Interestingly, in contrast to many other growth disorders like growth hormone deficiency or even idiopathic short stature, in SHOX deficiency females outnumber males. This phenomenon has been explained by the more severe phenotype in females which may cause ascertainment bias [30]. However, female predominance was also observed in SHOX mutation screening studies where the only phenotype targeted was short stature [29]. Therefore, ascertainment bias alone is unlikely to explain the gender dichotomy. Another explanation for the female preponderance in SHOX deficiency may be a genetic one: SHOX (X) deletions have been more frequently reported than SHOX (Y) deletions, which may indicate that the SHOX on the $\mathrm{X}$ is more prone to getting deleted than the SHOX on the Y.

In many children with SHOX deficiency below 6 years of age and in some boys above 6 years of age, there may be no characteristic sign of SHOX deficiency detectable in spite of a careful clinical evaluation. In this situation, the phenotype resembles the typical presentation of idiopathic short stature. However, the diagnosis made should not be idiopathic short stature but rather short stature due to SHOX deficiency [33].

\section{Madelung Deformity and Other Clinical Signs}

The wrist deformity associated with SHOX deficiency was first described by the German surgeon Dr. Otto Wilhelm Madelung in the year 1878 [34]. He described a 'spontaneous subluxation of the distal ulna forward' which gives the hand and forearm the appearance of a dinner fork. In minor, subtle, or immature forms of Madelung deformity, one can frequently observe a rotation deficit of the forearm with a reduction of the ability to supinate and to pronate. Shortening and broadening of the forearm may also appear before the full picture of Madelung deformity develops. There is a similar effect on the lower legs with bowing of the tibia and genu valgum. Because of the dominant inheritance, the examination of the wrists of the parents can give valuable hints in familial cases.

In addition to wrist deformity, there are several lessspecific signs in SHOX deficiency which are known from Turner syndrome. They are shortening of the fourth and fifth metacarpals, high arched palate, increased carrying angle of the elbow, scoliosis, and micrognathia [35]. In addition, muscular hypertrophy of the calves is found in one third of affected individuals [35]. Importantly, the absence of any of these signs including Madelung deformity does not exclude SHOX haploinsufficiency. 


\section{Growth and Auxology of SHOX Deficiency}

Most of the available information on the mean adult height in SHOX deficiency is biased by ascertainment. The least biased study screened all members of families with at least 1 index patient having Leri-Weill syndrome and calculated the mean adult height to be -2.2 SDS according to North American references [30]. Birth length in SHOX deficiency is only mildly reduced, but the height deficit is already present at preschool age suggesting that early childhood is the phase of growth failure $[29,30]$. Longitudinal data suggest the absence of catch-up growth at any time. Kosho et al. [36] reported an additional loss of height due to diminished pubertal growth in a small cohort of children; this second phase of growth failure, however, has not been confirmed by us and others $[29,30]$.

In SHOX deficiency, short stature is accompanied and to an important extent caused by (mesomelic) shortening of the extremities [29-31]. Therefore, clinical judgment requires measurement of the arm span and sitting height as well as calculation of the subischial leg length besides measurement of the standing height. In comparison to age-related reference standards, the arm span is significantly reduced in comparison to the standing height, and the leg length is significantly shorter than expected from the sitting height. In children less than 6 years of age, skeletal disproportions may be absent. A helpful parameter which integrates these 3 parameters is the extremitiestrunk ratio which was proposed by us (fig. 2). The ratio has the sum of the leg length and arm span in its numerator and the height of the trunk in its denominator. In children with SHOX deficiency, this ratio is significantly lower than in controls [29]. According to our data, a normal ratio in a school child excludes SHOX deficiency with a high negative predictive value at almost 100\% [29].

Auxology is also the core part of another scoring system for the diagnosis of SHOX deficiency proposed by Rappold et al. [35]. This score with 8 items was based on the data of 1,608 short individuals including 68 individuals with SHOX deficiency. The first 2 characteristics of this scoring system, namely the arm-span-to-height ratio and the sitting-height-to-height ratio, have the same targets as the above mentioned extremities-trunk ratio. Importantly, the limits given in percentage by this score are only valid in school children [37].

\section{Radiology of SHOX Deficiency}

The radiology of SHOX deficiency was described by Langer [38] when defining the radiological signs present in Leri-Weill syndrome. The main 3 signs are shown in

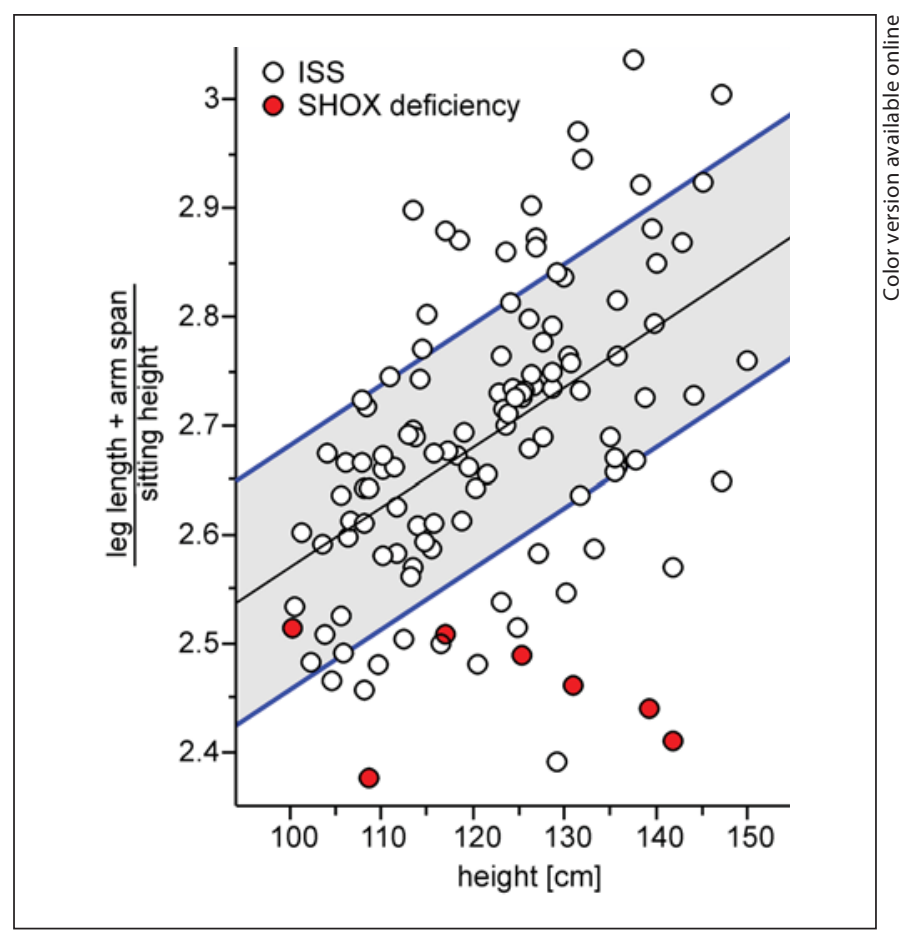

Fig. 2. Skeletal disproportions due to SHOX deficiency can be detected and quantified by the extremities-trunk ratio which is plotted against height in this figure. The mean ratio and 1 SD are indicated by lines. Each open circle indicates the ratio of a child with idiopathic short stature (ISS), and red circles (gray in the print version) are ratios from children with SHOX deficiency. With a ratio more than 1 SD below the mean at school age, SHOX deficiency is likely. A ratio above this limit in a school child (height $>110 \mathrm{~cm}$ ) excludes SHOX deficiency with a high negative predictive value at almost $100 \%$ [29].

figure 3 and are as follows: (i) the form of the distal radial epiphysis remains triangular instead of forming a trapezium at a bone age $>10$ years in females and $>11$ years in boys. This triangularization of the distal radial epiphysis is also present in girls with Turner syndrome, but not to the extent it is in Leri-Weill syndrome [39]; (ii) the carpal row becomes wedge shaped with the os lunatum building the tip of the pyramid which seems to invade the articular space (so-called pyramidalization of the carpal row), and (iii) the distal radius is radiographically lucent on the ulnar side where bone appears less dense than on the other side of the radius. This lucency can be a very early sign of SHOX deficiency because calcification of this part of the radius is present at birth [29]. Radiology can be regarded as more sensitive than clinical evaluation of the wrist in detecting signs of subtle Madelung deformity. 
Fig. 3. The main 3 radiological signs of SHOX deficiency and Leri-Weill syndrome are shown in comparison to normal hand X-rays in the top of the figure: triangularization of the distal radial epiphysis (bone age 13 years, female); pyramidalization of the carpal row which becomes wedge-shaped with the os lunatum building the tip of a pyramid (bone age 14 years, female), and radiographic lucency: the distal radius is radiographically lucent at the ulnar side where bone appears less dense than on the other side of the radius (bone age 10 years, female).

Fig. 4. This schema provides an algorithm approach to SHOX mutation screening in a short child. Minor abnormalities $\left(^{*}\right)$ in SHOX deficiency are shortening of the fourth and fifth metacarpals, high arched palate, increased carrying angle of the elbow, scoliosis, and micrognathia.
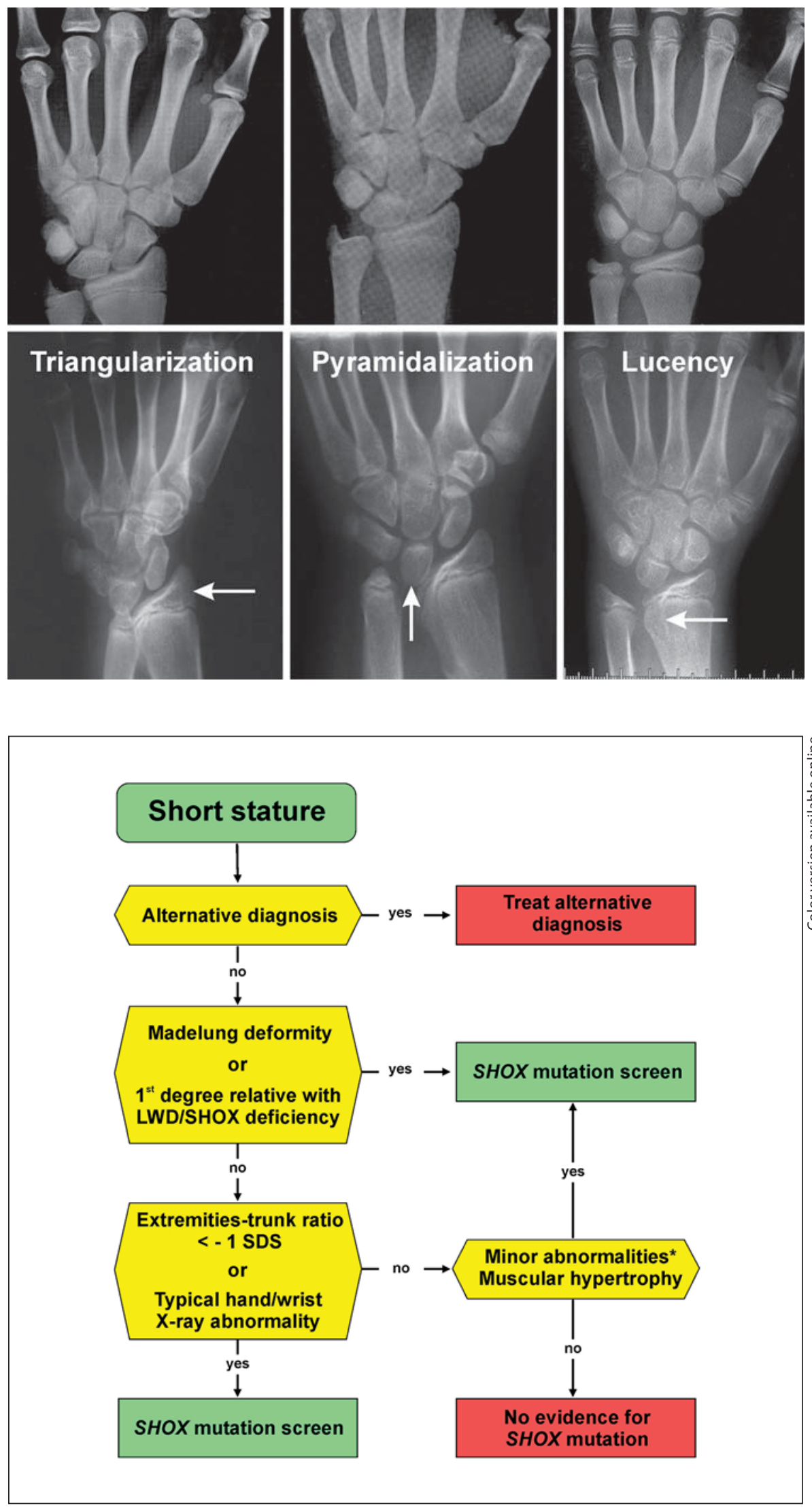


\section{Differential Diagnoses for SHOX Deficiency}

An algorithm approach to SHOX mutation screening in a short child is shown in figure 4 . The vast majority of cases with idiopathic short stature (85-98\%) are not caused by SHOX deficiency [13-15]. In around $10-50 \%$ of cases, Leri-Weill syndrome is not caused by SHOX deficiency $[16,17]$. In these instances, there is no approval for GH therapy in Europe.

Acquired Madelung deformity due to trauma or infection should be excluded by evaluation of the history. In males, deletions of SHOX can be associated with deletions of other genes on the X chromosome causing a contiguous gene deletion syndrome which can not be compensated for by the Y chromosome [40]. These boys may have ichthyosis, learning difficulties, Kallmann syndrome, and chondrodysplasia punctata. In females, Turner syndrome should be excluded by karyotyping.

\section{Therapy of Short Stature due to SHOX Deficiency}

After the initial discovery of SHOX mutations in 2 siblings from our clinic, recombinant $\mathrm{GH}$ was discussed as a potential drug for growth promotion. If SHOX deficiency is the main cause of short stature in girls with Turner syndrome, where GH therapy is efficient and safe, it seemed appropriate to perform a trial with GH in these short children [13]. This trial was efficient in the short term and in the long term $[13,41]$.

In the meantime, GH therapy has been approved by the FDA and EMEA based on the data of a randomized controlled trial. This 2-year prospective open-label parallel study randomized 2 cohorts of SHOX-deficient patients into a treatment group and a control group [42]. In parallel, a cohort of girls with Turner syndrome was treated with $\mathrm{GH}$. The mean age at the start of therapy was 7.5 years, and the $\mathrm{GH}$ dose was $50 \mu \mathrm{g} / \mathrm{kg} \cdot \mathrm{d}$.

The primary outcome variable was height velocity during the first year of therapy. The untreated cohort grew with a normal height velocity and their height SDS stayed unchanged. The GH-treated cohort grew faster and as fast as the girls with Turner syndrome treated in parallel. The treated group gained $3.5 \mathrm{~cm}$ in the first year and $1.9 \mathrm{~cm}$ in the second year in comparison to the untreated group [42].

In a retrospective study, final heights were evaluated from a group of children with SHOX deficiency who had been on GH treatment for more than 2 years. Although most of these children were treated with a low $\mathrm{GH}$ dose (mean initial dose $36 \mu \mathrm{g} / \mathrm{kg} \cdot \mathrm{d}$ ), the calculated overall gain in height $(7 \mathrm{~cm})$ was not different to the mean gain in height in treated Turner girls [41].

\section{Conclusions}

SHOX deficiency is frequently found (2-15\%) in individuals with formerly idiopathic short stature, causes Leri-Weill syndrome (dyschondrosteosis) in the majority of cases, and is involved in the short stature phenotype of Turner syndrome. The actual mutational analysis includes MLPA analysis followed by gene sequencing. Human expression is found in the early human embryo as well as in the child whose hypertrophic chondrocytes of the growth plate express $S H O X$. In vitro experiments suggest an antiproliferative potency of SHOX. The penetrance of SHOX deficiency is high but its clinical expression is very variable, becoming more pronounced with age and being more severe in females. Growth failure starts early during the first years of life, and the mean height reached is around 2 SD below the mean. Auxological analysis of the body proportions (mesomelia), the presence of some minor abnormalities, and the search for subtle radiographic signs are important keys to the diagnosis which has to be confirmed by genetic analysis. The growth-promoting effect of GH therapy which has been approved for growth promotion in individuals with SHOX mutations by FDA and EMEA seems to be equal to the effect reached in Turner syndrome. In the future, the elucidation of upstream and downstream partners of SHOX will help to understand the high clinical variability of SHOX deficiency and may provide new drug targets for growth promotion.

\section{Acknowledgements}

We are thankful to C. Philipp Schwarze for language editing and to Peter Michael Weber for preparation of the graphics.

\footnotetext{
References

$\nabla_{1}$ Rao E, Weiss B, Fukami M, Rump A, Niesler B, Mertz A, Muroya K, Binder G, Kirsch S, Winkelmann M, Nordsiek G, Heinrich U, Breuning $\mathrm{MH}$, Ranke MB, Rosenthal A, Ogata T, Rappold GA: Pseudoautosomal deletions encompassing a novel homeobox gene cause growth failure in idiopathic short stature and Turner syndrome. Nat Genet 1997; 16:54-63.

\2 Ellison JW, Wardak Z, Young MF, Gehron Robey P, Laig-Webster M, Chiong W: PHOG, a candidate gene for involvement in the short stature of Turner syndrome. Hum Mol Genet 1997;6:1341-1347.
} 
>3 Lien S, Szyda J, Schechinger B, Rappold G, Arnheim N: Evidence for heterogeneity in recombination in the human pseudoautosomal region: high resolution analysis by sperm typing and radiation-hybrid mapping. Am J Hum Genet 2000;66:557-566.

-4 Shears DJ, Vassal HJ, Goodman FR, Palmer RW, Reardon W, Superti-Furga A, Scambler PJ, Winter RM: Mutation and deletion of the pseudoautosomal gene SHOX cause LeriWeill dyschondrosteosis. Nat Genet 1998;19: 70-73.

5 Belin V, Cusin V, Viot G, Girlich D, Toutain A, Moncla A, Vekemans M, Le Merrer M, Munnich A, Cormier-Daire V: SHOX mutations in dyschondrosteosis (Leri-Weill syndrome). Nat Genet 1998;19:67-69.

6 Sabherwal N, Schneider KU, Blaschke RJ, Marchini A, Rappold G: Impairment of SHOX nuclear localization as a cause for Léri-Weill syndrome. J Cell Sci 2004;117: 3041-3048.

7 Schneider KU, Marchini A, Sabherwal N, Röth R, Niesler B, Marttila T, Blaschke RJ, Lawson M, Dumic M, Rappold G: Alteration of DNA binding, dimerization, and nuclear translocation of SHOX homeodomain mutations identified in idiopathic short stature and Leri-Weill dyschondrosteosis. Hum Mutat 2005;26:44-52.

$\checkmark 8$ Rao E, Blaschke RJ, Marchini A, Niesler B, Burnett M, Rappold GA: The Leri-Weill and Turner syndrome homeobox gene SHOX encodes a cell-type specific transcriptional activator. Hum Mol Genet 2001;10:3083-3091.

-9 Schiller S, Spranger S, Schechinger B, Fukami M, Merker S, Drop SL, Tröger J, Knoblauch H, Kunze J, Seidel J, Rappold GA: Phenotypic variation and genetic heterogeneity in Léri-Weill syndrome. Eur J Hum Genet 2000;8:54-62.

10 Sabherwal N, Bangs F, Röth R, Weiss B, Jantz K, Tiecke E, Hinkel GK, Spaich C, Hauffa BP, van der Kamp H, Kapeller J, Tickle C, Rappold G: Long-range conserved non-coding SHOX sequences regulate expression in developing chicken limb and are associated with short stature phenotypes in human patients. Hum Mol Genet 2007;16:210-222.

-11 Iughetti L, Capone L, Elsedfy H, Bertorelli R, Predieri B, Bruzzi P, Forabosco A, El Kholy $\mathrm{M}$ : Unexpected phenotype in a boy with trisomy of the SHOX gene. J Pediatr Endocrinol Metab 2010;23:159-169.

12 Benito-Sanz S, Barroso E, Heine-Suñer D, Hisado-Oliva A, Romanelli V, Rosell J, Aragones A, Caimari M, Argente J, Ross JL, Zinn AR, Gracia R, Lapunzina P, Campos-Barros A, Heath KE: Clinical and molecular evaluation of SHOX/PAR1 duplications in LeriWeill dyschondrosteosis (LWD) and idiopathic short stature (ISS). J Clin Endocrinol Metab 2010, E-pub ahead of print.
13 Binder G, Schwarze CP, Ranke MB: Identification of short stature caused by SHOX defects and therapeutic effect of recombinant human growth hormone. J Clin Endocrinol Metab 2000;85:245-249.

14 Rappold GA, Fukami M, Niesler B, Schiller S, Zumkeller W, Bettendorf M, Heinrich U, Vlachopapadoupoulou E, Reinehr T, Onigata K, Ogata T: Deletions of the homeobox gene SHOX (short stature homeobox) are an important cause of growth failure in children with short stature. J Clin Endocrinol Metab 2002;87:1402-1406.

15 Huber C, Rosilio M, Munnich A, CormierDaire V, French SHOX GeNeSIS Module: High incidence of SHOX anomalies in individuals with short stature. J Med Genet 2006; 43:735-739.

16 Binder G, Renz A, Martinez A, Keselman A, Hesse V, Riedl SW, Häusler G, Fricke-Otto S, Frisch H, Heinrich JJ, Ranke MB: SHOX haploinsufficiency and Leri-Weill dyschondrosteosis: prevalence and growth failure in relation to mutation, sex, and degree of wrist deformity. J Clin Endocrinol Metab 2004;89: 4403-4408.

$>17$ Flanagan SF, Munns CF, Hayes M, Williams B, Berry M, Vickers D, Rao E, Rappold GA, Batch JA, Hyland VJ, Glass IA: Prevalence of mutations in the short stature homeobox containing gene (SHOX) in Madelung deformity of childhood. J Med Genet 2002;39: 758-763.

-18 Zinn AR, Wei F, Zhang L, Elder FF, Scott CI Jr, Marttila P, Ross JL: Complete SHOX deficiency causes Langer mesomelic dysplasia. Am J Med Genet 2002;110:158-163.

19 Binder G, Eggermann T, Enders H, Ranke MB, Dufke A: Tall stature, gonadal dysgenesis, and stigmata of Turner's syndrome caused by a structurally altered $\mathrm{X}$ chromosome. J Pediatr 2001;138:285-287.

20 Thomas NS, Harvey JF, Bunyan DJ, Rankin J, Grigelioniene G, Bruno DL, Tan TY, Tomkins S, Hastings R: Clinical and molecular characterization of duplications encompassing the human SHOX gene reveal a variable effect on stature. Am J Med Genet 2009;149: 1407-1414.

21 Schouten JP, McElgunn CJ, Waaijer R, Zwijnenburg D, Diepvens F, Pals G: Relative quantification of 40 nucleic acid sequences by multiplex ligation-dependent probe amplification. Nucleic Acids Res 2002;30:e57.

22 Tiecke E, Bangs F, Blaschke R, Farrell ER, Rappold G, Tickle C: Expression of the short stature homeobox gene SHOX is restricted by proximal and distal signals in chick limb buds and affects the length of skeletal elements. Dev Biol 2006;298:585-596.

23 Marchini A, Daeffler L, Marttila T, Schneider KU, Blaschke RJ, Schnölzer M, Rommelaere J, Rappold G: Phosphorylation on Ser106 modulates the cellular functions of the SHOX homeodomain protein. J Mol Biol 2006;355:590-603.
24 Clement-Jones M, Schiller S, Rao E, Blaschke RJ, Zuniga A, Zeller R, Robson SC, Binder G, Glass I, Strachan T, Lindsay S, Rappold GA: The short stature homeobox gene SHOX is involved in skeletal abnormalities in Turner syndrome. Hum Mol Genet 2000;9:695-702.

25 Marchini A, Marttila T, Winter A, Caldeira S, Malanchi I, Blaschke RJ, Häcker B, Rao E, Karperien M, Wit JM, Richter W, Tommasino M, Rappold GA: The short stature homeodomain protein SHOX induces cellular growth arrest and apoptosis and is expressed in human growth plate chondrocytes. J Biol Chem 2004;279:37103-37114.

26 Munns CJ, Haase HR, Crowther LM, Hayes MT, Blaschke R, Rappold G, Glass IA, Batch JA: Expression of SHOX in human fetal and childhood growth plate. J Clin Endocrinol Metab 2004;89:4130-4135.

$\checkmark 27$ Marchini A, Häcker B, Marttila T, Hesse V, Emons J, Weiss B, Karperien M, Rappold G: $\mathrm{BNP}$ is a transcriptional target of the short stature homeobox gene SHOX. Hum Mol Genet 2007;16:3081-3087.

28 Munns CF, Glass IA, LaBrom R, Hayes M, Flanagan S, Berry M, Hyland VJ, Batch JA, Philips GE, Vickers D: Histopathological analysis of Leri-Weill dyschondrosteosis: disordered growth plate. Hand Surg 2001;6: $13-23$.

29 Binder G, Ranke MB, Martin DD: Auxology is a valuable instrument for the clinical diagnosis of SHOX haploinsufficiency in schoolage children with unexplained short stature. J Clin Endocrinol Metab 2003;88:48914896.

30 Ross JL, Scott C Jr, Marttila P, Kowal K, Nass A, Papenhausen P, Abboudi J, Osterman L, Kushner H, Carter P, Ezaki M, Elder F, Wei F, Chen H, Zinn AR: Phenotypes associated with SHOX deficiency. J Clin Endocrinol Metab 2001;86:5674-5680.

>31 Jorge AA, Souza SC, Nishi MY, Billerbeck AE, Libório DC, Kim CA, Arnhold IJ, Mendonca BB: SHOX mutations in idiopathic short stature and Leri-Weill dyschondrosteosis: frequency and phenotypic variability. Clin Endocrinol (Oxf) 2007;66:130-135.

>32 Ogata T, Matsuo N, Nishimura G: SHOX haploinsufficiency and overdosage: impact of gonadal function status. J Med Genet 2001;38:1-6.

-33 Cohen P, Rogol AD, Deal CL, Saenger P, Reiter EO, Ross JL, Chernausek SD, Savage MO, Wit JM, 2007 ISS Consensus Workshop participants: Consensus statement on the diagnosis and treatment of children with idiopathic short stature: a summary of the Growth Hormone Research Society, the Lawson Wilkins Pediatric Endocrine Society, and the European Society for Paediatric Endocrinology Workshop. J Clin Endocrinol Metab 2008;93:4210-4217.

34 Madelung OW: Die spontane Subluxation der Hand nach vorne. Verh Dtsch Ges Chir 1878;7:259-276. 
>35 Rappold G, Blum WF, Shavrikova EP, Crowe BJ, Roeth R, Quigley CA, Ross JL, Niesler B: Genotypes and phenotypes in children with short stature: clinical indicators of SHOX haploinsufficiency. J Med Genet 2007;44: 306-313.

-36 Kosho T, Muroya K, Nagai T, Fujimoto M, Yokoya S, Sakamoto H, Hirano T, Terasaki H, Ohashi H, Nishimura G, Sato S, Matsuo N, Ogata T: Skeletal features and growth patterns in 14 patients with haploinsufficiency of SHOX: implications for the development of Turner syndrome. J Clin Endocrinol Metab 1999;84:4613-4621.

>37 Jorge AA, Arnhold IJ: Anthropometric evaluation of children with SHOX mutations can be used as indication for genetic studies in children of short stature. J Med Genet 2007; 44:e90.
38 Langer LO Jr: Dyschondrosteosis, a heritable bone dysplasia with characteristic roentgenographic features. Am J Roentgenol Radium Ther Nucl Med 1965;95:178-188.

39 Binder G, Fritsch H, Schweizer R, Ranke MB: Radiological signs of Leri-Weill dyschondrosteosis in Turner syndrome. Horm Res 2001; 55:71-76.

40 Spranger S, Schiller S, Jauch A, Wolff K, Rauterberg-Ruland I, Hager D, Tariverdian G, Tröger J, Rappold G: Léri-Weill syndrome as part of a contiguous gene syndrome at Xp22.3. Am J Med Genet 1999;83:367-371.

41 Blum WF, Cao D, Hesse V, Fricke-Otto S, Ross JL, Jones C, Quigley CA, Binder G: Height gains in response to growth hormone treatment to final height are similar in patients with SHOX deficiency and Turner syndrome. Horm Res 2009;71:167-172.
42 Blum WF, Crowe BJ, Quigley CA, Jung H, Cao D, Ross JL, Braun L, Rappold G, SHOX Study Group: Growth hormone is effective in treatment of short stature associated with short stature homeobox-containing gene deficiency: two-year results of a randomized, controlled, multicenter trial. J Clin Endocrinol Metab 2007;92:219-228.

43 Mangs HA, Morris BJ: The human pseudoautosomal region (PAR): origin, function and future. Curr Genomics 2007;8:129-136.

44 Blaschke RJ, Rappold GA: SHOX in short stature syndromes. Horm Res 2001;55(suppl 1):21-23. 